\title{
Reflex cough PEF as a predictor of successful extubation in neurological patients*
}

\author{
Pico de fluxo de tosse reflexa como preditor de sucesso \\ na extubação em pacientes neurológicos
}

\author{
Fernanda Machado Kutchak ${ }^{1,2}$, Andressa Maciel Debesaitys ${ }^{2}$, \\ Marcelo de Mello Rieder ${ }^{2,3}$, Carla Meneguzzi ${ }^{2}$, Amanda Soares Skueresky ${ }^{3}$, \\ Luiz Alberto Forgiarini Junior ${ }^{3,4}$, Marino Muxfeldt Bianchin ${ }^{5}$
}

\begin{abstract}
Objective: To evaluate the use of reflex cough PEF as a predictor of successful extubation in neurological patients who were candidates for weaning from mechanical ventilation. Methods: This was a cross-sectional study of 135 patients receiving mechanical ventilation for more than $24 \mathrm{~h}$ in the ICU of Cristo Redentor Hospital, in the city of Porto Alegre, Brazil. Reflex cough PEF, the rapid shallow breathing index, MIP, and MEP were measured, as were ventilatory, hemodynamic, and clinical parameters. Results: The mean age of the patients was $47.8 \pm 17$ years. The extubation failure rate was 33.3\%. A reflex cough PEF of $<80 \mathrm{~L} / \mathrm{min}$ showed a relative risk of 3.6 (95\% Cl: 2.0-6.7), and the final Glasgow Coma Scale score showed a relative risk of $0.64(95 \% \mathrm{Cl}$ : 0.51-0.83). For every 1-point increase in a Glasgow Coma Scale score of 8, there was a 36\% reduction in the risk of extubation failure. Conclusions: Reflex cough PEF and the Glasgow Coma Scale score are independent predictors of extubation failure in neurological patients admitted to the ICU.
\end{abstract}

Keywords: Weaning; Intensive care units; Cough.

\section{Introduction}

Mechanical ventilation (MV) is an important tool in the treatment of respiratory failure in patients with acute disease or acute exacerbation of chronic disease; however, patients should be weaned from MV as soon as the condition leading to their being placed on MV is resolved. ${ }^{(1)}$ Screening tests can be used in order to make decisions regarding weaning and extubation, which have been the subject of many studies in recent decades. ${ }^{(1)}$

Weaning failure is often attributed to impaired gas exchange, respiratory muscle fatigue, and an imbalance between respiratory load and ventilatory demand; however, in patients with neurological injury, impaired airway protection can be one of the reasons for weaning failure. ${ }^{(2,3)}$
The parameter that is most commonly used in order to evaluate the ability of patients to breathe spontaneously and weaning potential is the ratio between RR and tidal volume, which is known as the rapid shallow breathing index (RSBI). ${ }^{(4)}$ Although the RSBl is widely used, it has not proved to be a reliable predictor in patients with neurological injury. ${ }^{(5-10)}$ In such patients, extubation failure appears to be more closely related to their inability to protect the airway than to their ability to breathe spontaneously. ${ }^{(11)}$

In 20\% of patients admitted to the ICU, acute neurological disorders (neuromuscular disease, in $10 \%$, and coma or central nervous system dysfunction, in 10\%) are the main reasons for initiating invasive MV. ${ }^{(12)}$ Therefore, there is a

*Study carried out at the Unidade de Terapia Intensiva, Hospital Cristo Redentor, Porto Alegre (RS) Brasil.

1. Universidade do Vale do Rio dos Sinos - UNISINOS - São Leopoldo (RS) Brasil.

2. Unidade de Terapia Intensiva, Hospital Cristo Redentor, Porto Alegre (RS) Brasil.

3. Curso de Fisioterapia, Centro Universitário Metodista, Instituto Porto Alegre (RS) Brasil.

4. Programa de Pós-Graduação em Biociências e Reabilitação, Centro Universitário Metodista, Instituto Porto Alegre, Porto Alegre (RS) Brasil.

5. Serviço de Neurologia, Hospital de Clínicas de Porto Alegre, Universidade Federal do Rio Grande do Sul - UFRGS - Porto Alegre (RS) Brasil.

Correspondence to: Fernanda Machado Kutchak. Unidade de Terapia Intensiva, Hospital Cristo Redentor. Rua Domingos Rubbo, 20, CEP 91040-000, Porto Alegre, RS, Brasil.

Tel. 5551 9136-5947.E-mail: fkutchak@unisinos.br

Financial support: None.

Submitted: 20 October 2014. Accepted, after review: 20 April 2015. 
need for parameters that are more accurate in order to make weaning decisions in such patients.

Cough effectiveness or strength before extubation, as measured by voluntary cough PEF with an open glottis, has been studied as a predictor of the ability to protect the airway after extubation in critically ill patients, being an important measure of airway protection ability. ${ }^{(13-18)}$ However, there are physiological differences in motor activation of expiratory and accessory muscles between voluntary and reflex cough; the latter is associated with widespread and simultaneous activation of expiratory and accessory muscles, generating two or more PEFs of lower amplitude when compared with the former. ${ }^{(19)}$

The objective of the present study was to evaluate the use of reflex cough PEF as a predictor of successful extubation in neurological patients who were candidates for weaning from MV.

\section{Methods}

This was a cross-sectional study conducted in the ICU of Cristo Redentor Hospital, in the city of Porto Alegre, Brazil, between January of 2011 and June of 2013. The research project was approved by the Research Ethics Committee of the Conceição Hospital Group (Protocol no. 10-150).

The inclusion criteria were as follows: being on MV for more than $24 \mathrm{~h}$; having been placed on MV because of a neurological condition; and being a candidate for weaning from MV.

The criteria for extubation were as follows: adequate oxygenation, with an $\mathrm{FiO}_{2}$ of $<0.4$; hemodynamic stability (HR of < $130 \mathrm{bpm}$ ); mean arterial pressure $>60 \mathrm{mmHg}$ with minimal or no use of vasopressors; axillary temperature of < $37.5^{\circ} \mathrm{C}$; hemoglobin level > $8 \mathrm{~g} / \mathrm{dL}$; Glasgow Coma Scale score $\geq 8$; and acid-base and electrolyte balance.

A digital manometer (MVD-500 v.1.1; Globalmed, Porto Alegre, Brazil) was used in order to measure MIP and MEP, the best of three consecutive maximal inspiratory and expiratory maneuvers performed with the one-way valve closed for $30 \mathrm{~s}$ being recorded. The RSBl was measured immediately before a spontaneous breathing trial (SBT), by means of a spirometer connected to the endotracheal tube. The Glasgow Coma Scale score and reflex cough PEF were determined by the Cristo Redentor Hospital ICU physical therapy team immediately before the SBT, with the head of the bed elevated $45^{\circ}$.

A portable peak flow meter (Mini-Wright AFS; Clement Clarke International Limited, Harlow, England) was used in order to measure reflex cough PEF. The peak flow meter was connected to the endotracheal tube via a T-piece with a one-way valve to allow free inhalation and exhalation through it. To initiate the cough reflex, mechanical stimulation was provided by introducing an $8 \mathrm{~F}$ suction catheter through the nose; when the stimulation delivered above the glottis was insufficient to elicit cough, the catheter was inserted into the endotracheal tube through the front opening of the T-piece in order to stimulate tracheal receptors.

The SBT was performed with a T-tube and supplemental oxygen (maximum $\mathrm{FiO}_{2}$ of $40 \%$ ) for $30 \mathrm{~min}$. Extubation failure was defined as the need for reintubation within less than $48 \mathrm{~h}$ after extubation. All clinical and demographic data were collected from the medical records of the patients. The need for reintubation was determined by the attending physician, and the information regarding the reasons for reintubation was collected from the medical records of the patients.

The Statistical Package for the Social Sciences, version 18.0 (SPSS Inc., Chicago, IL, USA) was used for statistical analysis. The Kolmogorov-Smirnov test was used in order to determine whether the data were normally distributed. Continuous variables were expressed as means and standard deviations or medians and interquartile ranges, whereas categorical variables were expressed as percentages. The Student's t-test or the Mann-Whitney test (for continuous variables) and Pearson's chi-square test or Fisher's exact test (for categorical variables) were used. The relative risk was calculated in order to determine the associations among predictor variables. Variables with a value of $p<0.2$ were included in the multivariate analysis in order to compare extubation success and failure rates. To evaluate the predictive ability of reflex cough PEF, Glasgow Coma Scale scores, and the RSBl, sensitivity, specificity, and accuracy were measured with a ROC curve. The level of statistical significance was set at $p<0.05$.

\section{Results}

A total of 135 neurological patients extubated between January of 2011 and June of 2013 were 
included in the present study. The mean age of the patients was $47.8 \pm 17$ years. Male patients predominated $(71.1 \%)$, and the extubation failure rate was 33.3\%.

The most common clinical diagnosis was that of traumatic brain injury, in 62 patients (47\%), followed by those of subarachnoid hemorrhage, in 35.6\%, intracranial hemorrhage, in 11.4\%, and brain tumor (in the postoperative period), in $6.1 \%$. Other clinical characteristics of the sample are presented in Table 1. Of the patients who required reintubation, $7 \%$ did so because of a decreased level of consciousness, $31 \%$ did so because of accumulation of bronchial secretions, and $62 \%$ did so because they were unable to protect their airway.

With regard to the ventilatory, hemodynamic, and gas exchange parameters related to the SBT, there were no statistically significant differences between the patients in whom extubation was successful and those in whom extubation failed (Table 2). However, there were statistically significant differences between the two groups of patients regarding the length of ICU stay, the length of hospital stay, and mortality (Table 3).

A reflex cough PEF of $<80 \mathrm{~L} / \mathrm{min}$ and the Glasgow Coma Scale score proved to be independent predictors of extubation failure. A reflex cough PEF of $<80 \mathrm{~L} / \mathrm{min}$ showed a relative risk of 3.6 (95\% Cl: 2.0-6.7; $p<0.001)$, and the final Glasgow Coma Scale score showed a relative risk of $0.64(95 \% \mathrm{Cl}: 0.51-0.83 ; \mathrm{p}<$
0.001). For every 1-point increase in a Glasgow Coma Scale score of 8 , there was a 36\% reduction in the risk of extubation failure. Similarly, the ROC curve showed that reflex cough PEF and the Glasgow Coma Scale score are good predictors of successful extubation (Figure 1). It is of note that the accuracy of the RSBl in predicting successful extubation was low in our sample of patients.

\section{Discussion}

The present study showed that reflex cough PEF can be a predictor of successful extubation in neurological patients who are candidates for weaning from MV.

It is known that $20 \%$ of all individuals admitted to the ICU require ventilatory support because of acute neurological complications. ${ }^{(10)}$ Although there have been reports of successful extubation in such patients, it is important to assess their mental state and their ability to protect the airway. ${ }^{(20)}$ Studies have shown that patients with traumatic brain injury and subarachnoid hemorrhage have a $20-45 \%$ chance to develop ventilator-associated pneumonia, MV being directly related to prolonged ICU stay and mortality. ${ }^{(14,15)}$ In our study, ventilator-associated pneumonia was more common in the patients whose extubation failed than in those whose extubation was successful.

In addition to increasing hospitalization costs significantly, extubation failure is associated

Table 1 - Clinical and epidemiological characteristics of the 135 patients studied, together with their ventilatory parameters. ${ }^{a}$

\begin{tabular}{|c|c|c|c|c|}
\hline Variable & $\begin{array}{c}\text { Total } \\
(n=135)\end{array}$ & $\begin{array}{c}\text { Extubation success } \\
\qquad(\mathrm{n}=90)\end{array}$ & $\begin{array}{c}\text { Extubation failure } \\
(\mathrm{n}=45)\end{array}$ & $p$ \\
\hline Age, years & $47.80 \pm 17.01$ & $48.17 \pm 17.50$ & $49.82 \pm 16.93$ & $0.875^{b}$ \\
\hline Male gender, n (\%) & $96(71.10)$ & $66(73.30)$ & $30(66.70)$ & $0.561^{c}$ \\
\hline APACHE 11 score & $18.87 \pm 5.41$ & $18.20 \pm 5.70$ & $20.40 \pm 4.40$ & $0.024^{\mathrm{b}}$ \\
\hline GCS at admission & $7.77 \pm 2.14$ & $7.94 \pm 2.12$ & $7.20 \pm 2.16$ & $0.79^{b}$ \\
\hline GCS score at extubation & $9.69 \pm 1.12$ & $10.07 \pm 0.93$ & $8.90 \pm 0.51$ & $<0.001^{b}$ \\
\hline PEEP, $\mathrm{cmH}_{2} \mathrm{O}$ & $5.27 \pm 0.46$ & $5.25 \pm 0.45$ & $5.31 \pm 0.47$ & 0.516 \\
\hline $\mathrm{FiO}_{2}, \%$ & $34 \pm 0.49$ & $34 \pm 0.41$ & $34 \pm 0.63$ & $0.921^{\mathrm{b}}$ \\
\hline $\mathrm{V}_{\mathrm{T}}, \mathrm{mL}$ & $522 \pm 134$ & $535 \pm 135.40$ & $493 \pm 121$ & $0.180^{\mathrm{b}}$ \\
\hline Duration of MV, days ${ }^{\mathrm{d}}$ & $8.62 \pm 5.70$ & $7.21 \pm 4.85$ & $11.46 \pm 6.26$ & $<0.001^{\mathrm{d}}$ \\
\hline $\mathrm{MIP}, \mathrm{cmH}_{2} \mathrm{O}^{\mathrm{d}}$ & $65.22 \pm 23.81$ & $70.43 \pm 22.30$ & $54.80 \pm 23.53$ & $<0.001^{\mathrm{d}}$ \\
\hline MEP, $\mathrm{cmH}_{2} \mathrm{O}^{\mathrm{d}}$ & $69.10 \pm 43.87$ & $75.65 \pm 48.80$ & $55.73 \pm 27.59$ & $0.003^{\mathrm{d}}$ \\
\hline $\mathrm{RSBl}$, breaths/min/L & $46.34 \pm 17.79$ & $43.86 \pm 16.76$ & $51.30 \pm 18.92$ & $0.028^{\mathrm{d}}$ \\
\hline Reflex cough PEF & $102.09 \pm 41.13$ & $115.34 \pm 38.95$ & $75.76 \pm 31.23$ & $<0.001^{b}$ \\
\hline
\end{tabular}

APACHE 11: Acute Physiology and Chronic Health Evaluation 11; GCS: Glasgow Coma Scale; PEEP: positive end-expiratory pressure; $\mathrm{V}_{\mathrm{T}}$ : tidal volume; MV: mechanical ventilation; and $\mathrm{RSBl}$ : rapid shallow breathing index. ${ }^{\mathrm{V} V}$ alues expressed as mean \pm SD. 'Student's t-test. 'Pearson's chi-square test. 'Mann-Whitney test. 
Table 2 - Ventilatory, hemodynamic, and gas exchange parameters measured within 30 min after initiation of a spontaneous breathing trial. ${ }^{\mathrm{a}}$

\begin{tabular}{lccc}
\hline \multicolumn{1}{c}{ Variable } & Extubation success & Extubation failure & \multirow{2}{*}{$\mathrm{p}^{\mathrm{b}}$} \\
\cline { 2 - 4 } $\mathrm{SBP}, \mathrm{mmHg}$ & $\mathrm{n}=90)$ & $(\mathrm{n}=45)$ & \\
$\mathrm{DBP}, \mathrm{mmHg}$ & $138 \pm 22$ & $140 \pm 16$ & 0.411 \\
$\mathrm{HR}, \mathrm{bpm}$ & $80 \pm 11$ & $81 \pm 8.90$ & 0.677 \\
$\mathrm{RR}$, breaths/min & $89 \pm 12$ & $88 \pm 12$ & 0.838 \\
Arterial blood gases, $\mathrm{pH}$ & $23 \pm 8.90$ & $25 \pm 3.80$ & 0.359 \\
$\mathrm{PaCO}_{2}, \mathrm{mmHg}$ & $7.40 \pm 0.31$ & $7.40 \pm 0.03$ & 0.436 \\
$\mathrm{PaO}_{2}, \mathrm{mmHg}$ & $40 \pm 6.20(5.37 \pm 0.83)$ & $39 \pm 5.47(5.16 \pm 0.73)$ & 0.177 \\
$\mathrm{SaO}_{2}, \%$ & $117 \pm 35(15.60 \pm 4.67)$ & $125 \pm 31(16.67 \pm 4.13)$ & 0.243 \\
$\mathrm{PaO}_{2} / \mathrm{FiO}_{2}$ & $98 \pm 1.51$ & $98 \pm 1.75$ & 0.230 \\
\hline $\mathrm{SBP}_{\mathrm{Sys}}$ & $346 \pm 116$ & $356 \pm 112$ & 0.507 \\
\hline
\end{tabular}

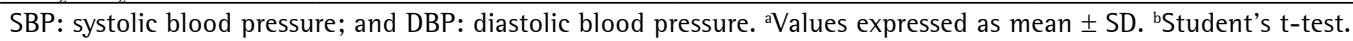

Table 3 - Outcomes in the patients in whom extubation was successful and in those in whom extubation failed. $^{\mathrm{a}}$

\begin{tabular}{|c|c|c|c|}
\hline \multirow[t]{2}{*}{ Variable } & Extubation success & Extubation failure & \multirow[t]{2}{*}{$\mathrm{p}$} \\
\hline & $(n=90)$ & $(n=45)$ & \\
\hline Length of ICU stay ${ }^{b}$ & $12(7-17)$ & $17(14-23)$ & $<0.001^{\mathrm{c}}$ \\
\hline Length of hospital stayb & $25(17-30)$ & $30(21-52)$ & $0.009^{c}$ \\
\hline Outcome of hospitalization & & & $0.017^{\mathrm{d}}$ \\
\hline Discharge & 77 (85.6) & $29(64.4)$ & \\
\hline Death & $4(4.4)$ & $9(20)^{\mathrm{e}}$ & \\
\hline Transfer & $9(10)$ & $7(15)$ & \\
\hline Outcome of ICU care & & & $<0.001^{\mathrm{d}}$ \\
\hline Discharge & $84(93.3)$ & $38(84.4)$ & \\
\hline Death & $1(1.1)$ & $6(13.6)^{e}$ & \\
\hline Transfer & $5(5.6)$ & $1(2.2)$ & \\
\hline VAP & $32(35.5)$ & $24(53.3)$ & 0.027 \\
\hline
\end{tabular}

VAP: ventilator-associated pneumonia. ${ }^{a}$ Values expressed as $n(\%)$, except where otherwise indicated. ${ }^{\text {bValues expressed }}$

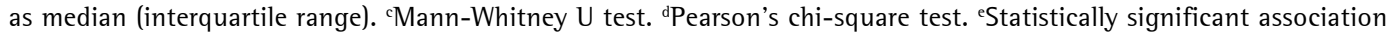
with adjusted standardized residuals (level of significance of 5\%).
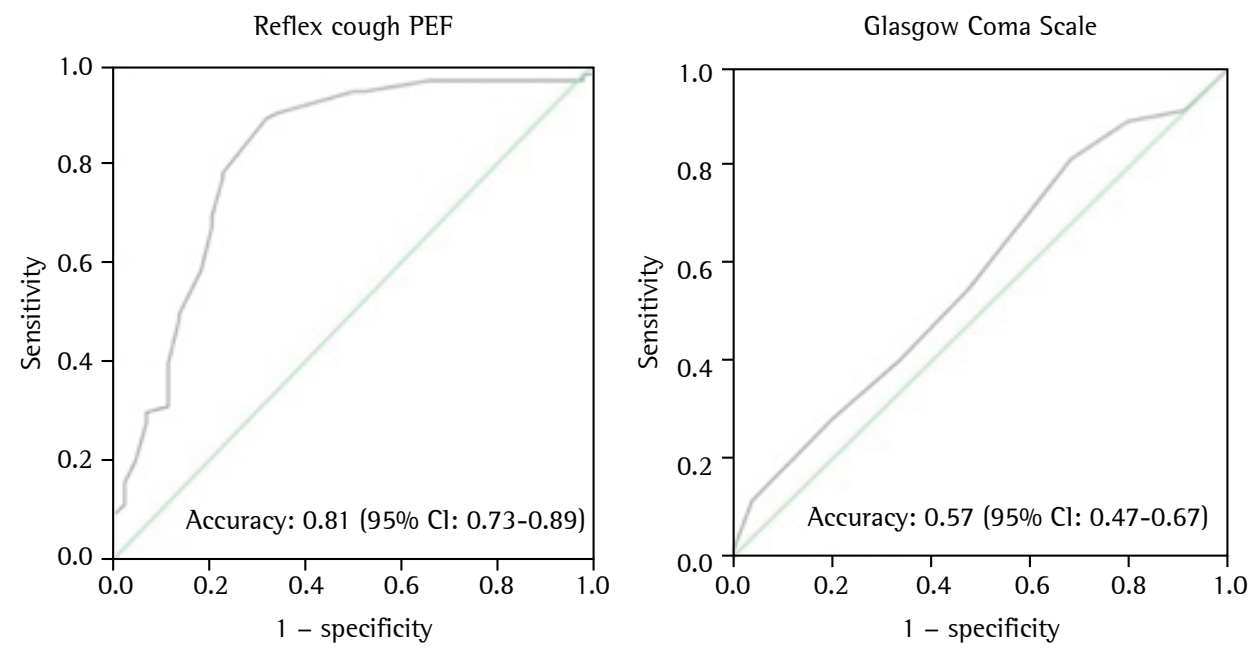

Figure 1 - Accuracy of reflex cough PEF and Glasgow Coma Scale scores in predicting successful extubation in neurological patients admitted to the ICU. 
with prolonged MV, an increased incidence of ventilator-associated pneumonia, and an increased risk of mortality. ${ }^{(16-18,21-24)} \mathrm{ln}$ the present study, pneumonia was significantly more common, mortality rates were significantly higher, and ICU and hospital stays were significantly longer in the patients in whom extubation failed, findings that are consistent with the literature.

The influence of age on weaning outcomes can vary depending on the population studied. ${ }^{(24)}$ In the present study, there was no significant association between patient age and MV weaning outcomes. This finding is consistent with those of other studies of patients with neurological injury, suggesting that age is not an important predictor of MV weaning outcomes in such patients..$^{(9-11)}$

Our study population consisted predominantly of males (71.1\%). Epidemiologically, this is due to the fact that the ICU of Cristo Redentor Hospital is a trauma $1 \mathrm{CU}$, where the prevalence of male patients is associated with lifestyle or greater exposure to risk factors for traumatic brain injury. ${ }^{(25)}$

In the present study, there were no significant differences between the patients in whom extubation was successful and those in whom extubation failed in terms of the ventilatory, hemodynamic, and gas exchange parameters during the SBT. This finding is consistent with those of studies of neurological patients, in whom the major obstacles to weaning and extubation are associated with their inability to protect the airway rather than with their inability to breathe spontaneously, given that there are no differences between the groups. ${ }^{(9,10)}$

In the present study, there were significant differences between the patients in whom extubation was successful and those in whom extubation failed regarding the RSBl, MIP, and MEP evaluated separately. However, in the multivariate analysis, there were no significant differences between the two groups of patients regarding those parameters. Although they are among the most widely assessed parameters for weaning and extubation, they are not good predictors of extubation failure in neurological patients. ${ }^{(6-10)}$ The accuracy of the RSBI in predicting successful extubation was found to be low in the present study. This finding is consistent with those of previous studies, showing that the RSBI is not a good predictor in such patients..$^{(9,10)}$

Consciousness level assessment by the Glasgow Coma Scale is extremely important in neurological patients. A study by Namen et al. showed that the Glasgow Coma Scale score was associated with successful extubation regardless of the protocol used; a score $\geq 8$ was associated with successful extubation in 75\% of cases, whereas a score of $<8$ was associated with successful extubation in $33 \%$ of cases. ${ }^{(26,27)}$

In the present study, all patients had a Glasgow Coma Scale score $>8$, the mean score being 10.07 \pm 0.93 points in the group of patients in whom extubation was successful and $8.9 \pm 0.51$ points in the group of patients in whom extubation failed. Our logistic regression analysis showed that a Glasgow Coma Scale score of 8 is an independent predictor of extubation failure, every 1-point increase in that score reducing the risk of extubation failure by $36 \%$. The present study showed that the Glasgow Coma Scale score has good accuracy in predicting successful weaning in neurological patients. These findings are similar to those of Namen et al., who demonstrated that the chances of success increased by 30\% for every 1-point increase in the Glasgow Coma Scale score. ${ }^{(26)}$ Vidotto et al. studied 92 neurosurgical patients who had Glasgow Coma Scale scores $\geq 8$ and who were extubated after an SBT and noted that $16 \%$ required reintubation. ${ }^{(4)}$ Mokhelesi et al. found similar rates, with an extubation failure rate of $50 \%$ for scores $\leq 10$ and of $9 \%$ for scores $>10 . .^{(28)}$

Airway protection can be evaluated by measuring peak cough flow (PCF) with a peak flow meter or a pneumotachograph. Analysis of PCF as measured with a peak flow meter in 95 patients before extubation showed that PCF was significantly lower in those in whom extubation failed than in those in whom extubation was successful $(64.2 \pm 6.8 \mathrm{~L} / \mathrm{min}$ vs. $81.9 \pm 2.7 \mathrm{~L} /$ $\mathrm{min}$ ); the risk of extubation failure was 5.1 times higher in those in whom PCF was lower than $60 \mathrm{~L} / \mathrm{min}^{(15)}$ However, analysis of PCF as measured with a pneumotachograph showed that PCF was similar between the patients in whom extubation was successful and those in whom extubation failed, mean PCF values being $79.7 \mathrm{~L} / \mathrm{min}$ and $58.1 \mathrm{~L} / \mathrm{min}$, respectively. ${ }^{(7)}$ The differences between the two aforementioned studies regarding PCF values can be explained by the different measurement instruments used. In a study of 150 patients admitted to a medical $1 C U,{ }^{(29)}$ reflex cough PEF was measured with a portable respiratory mechanics monitor. Mean 
reflex cough PEF was $74 \mathrm{~L} / \mathrm{min}$ in the patients whose extubation was successful and $42 \mathrm{~L} / \mathrm{min}$ in those whose extubation failed. ${ }^{(29)}$ The authors of that study concluded that PCF is a potential predictor of successful extubation in patients who pass an SBT. ${ }^{(29)}$

The present study has some limitations. Mean reflex cough PEF values $(115.34 \pm 38.95 \mathrm{~L} / \mathrm{min}$ in the patients in whom extubation was successful and $75.76 \pm 31.23 \mathrm{~L} / \mathrm{min}$ in those in whom extubation failed) were higher than those found in the literature. This difference can be partly explained by the use of a portable peak flow meter and by the fact that the study population consisted solely of patients with neurological injury, unlike the clinical populations evaluated in other studies. It is of note that reference values for reflex cough PEF have yet to be established, and that studies aimed at doing so can be useful in determining the best timing for weaning and extubation. ${ }^{(30)}$

Although several studies have suggested that it is essential to evaluate cough and, consequently, airway protection ability before extubation,,$^{(7,15,23)}$ there is still no consensus on the methodology to be used or on cut-off points to predict extubation outcomes.

We can conclude that reflex cough PEF as measured with a peak flow meter and the Glasgow Coma Scale score are independent predictors of extubation failure in neurological patients admitted to the ICU.

\section{References}

1. Tanios MA, Nevins ML, Hendra KP, Cardinal P, Allan JE, Naumova EN, et al. A randomized, controlled trial of the role of weaning predictors in clinical decision making. Crit Care Med. 2006;34(10):2530-5. http:// dx.doi.org/10.1097/01.CCM.0000236546.98861.25

2. Sprague SS, Hopkins PD. Use of inspiratory strength training to wean six patients who were ventilatordependent. Phys Ther. 2003;83(2):171-81.

3. Yang KL. Inspiratory pressure/maximal inspiratory pressure ratio: a predictive index of weaning outcome. Intensive Care Med. 1993;19(4):204-8. http://dx.doi.org/10.1007/ BF01694771

4. Vidotto MC, Sogame LC, Calciolari CC, Nascimento OA, Jardim JR. The prediction of extubation success of postoperative neurosurgical patients using frequency-tidal volume ratios. Neurocrit Care. 2008;9(1):83-9. http:// dx.doi.org/10.1007/s12028-008-9059-X

5. Salam A, Tilluckdharry L, Amoateng-Adjepong Y, Manthous CA. Neurologic status, cough, secretions and extubation outcomes. Intensive Care Med. 2004;30(7):1334-9. http:// dx.doi.org/10.1007/s00134-004-2231-7
6. Stevens RD, Lazaridis C, Chalela JA. The role of mechanical ventilation in acute brain injury. Neurol Clin. 2008;26(2):543-63, x. http://dx.doi.org/10.1016/j. ncl.2008.03.014

7. Ko R, Ramos L, Chalela JA. Conventional weaning parameters do not predict extubation failure in neurocritical care patients. Neurocrit Care. 2009;10(3):269-73. http:// dx.doi.org/10.1007/s12028-008-9181-9

8. Anderson CD, Bartscher JF, Scripko PD, Biffi A, Chase D, Guanci M, et al. Neurologic examination and extubation outcome in the neurocritical care unit. Neurocrit Care. 2011;15(3):490-7. http://dx.doi.org/10.1007/ s12028-010-9369-7

9. Nemer SN, Barbas CS. Predictive parameters for weaning from mechanical ventilation. J Bras Pneumol. 2011;37(5):669-79. http://dx.doi.org/10.1590/ S1806-37132011000500016

10. Brazilian recommendations of mechanical ventilation 2013. Part 2. J Bras Pneumol. 2014;40(5):458-86. http:// dx.doi.org/10.1590/S1806-37132014000500003

11. Navalesi P, Frigerio P, Moretti MP, Sommariva M, Vesconi $\mathrm{S}$, Baiardi $\mathrm{P}$, et al. Rate of reintubation in mechanically ventilated neurosurgical and neurologic patients: evaluation of a systematic approach to weaning and extubation. Crit Care Med. 2008;36(11):2986-92. http://dx.doi. org/10.1097/CCM.0b013e31818b35f2

12. Esteban A, Anzueto A, Alía 1, Gordo F, Apezteguía C, Pálizas $F$, et al. How is mechanical ventilation employed in the intensive care unit? An international utilization review. Am J Respir Crit Care Med. 2000;161(5):1450-8. http://dx.doi.org/10.1164/ajrccm.161.5.9902018

13. Berti ME, Broggi R, Clos P, Cóppola L, Díaz CL, Dursi F, et al. Comportamiento de las variables de protección de la vía aérea al momento de la extubación. Med Intensiva. 2004;21(1):7-14.

14. Khamiees M, Raju P, DeGirolamo A, Amoateng-Adjepong $Y$, Manthous CA. Predictors of extubation outcome in patients who have successfully completed a spontaneous breathing trial. Chest. 2001;120(4):1262-70. http:// dx.doi.org/10.1378/chest.120.4.1262

15. Smina M, Salam A, Khamiees M, Gada P, AmoatengAdjepong Y, Manthous CA. Cough peak flows and extubation outcomes. Chest. 2003;124(1):262-8. http:// dx.doi.org/10.1378/chest.124.1.262

16. Kallel H, Chelly H, Bahloul M, Ksibi H, Dammak H, Chaari $A$, et al. The effect of ventilator-associated pneumonia on the prognosis of head trauma patients. J Trauma. 2005;59(3):705-10.

17. Zygun DA, Zuege DJ, Boiteau PJ, Laupland KB, Henderson EA, Kortbeek JB, et al. Ventilator-associated pneumonia in severe traumatic brain injury. Neurocrit Care. 2006;5(2):108-14. http://dx.doi.org/10.1385/ NCC:5:2:108

18. Epstein SK, Ciubotaru RL, Wong JB. Effect of failed extubation on the outcome of mechanical ventilation. Chest. 1997;112(1):186-92. http://dx.doi.org/10.1378/ chest.112.1.186

19. Lasserson D, Mills K, Arunachalam R, Polkey M, Moxham $\mathrm{J}$, Kalra L. Differences in motor activation of voluntary and reflex cough in humans. Thorax. 2006;61(8):699705. http://dx.doi.org/10.1136/thx.2005.057901

20. Coplin WM, Pierson DJ, Cooley KD, Newell DW, Rubenfeld GD. Implications of extubation delay in brain-injured patients meeting standard weaning criteria. Am J Respir 
Crit Care Med. 2000;161(5):1530-6. http://dx.doi. org/10.1164/ajrccm.161.5.9905102

21. Maclntyre NR, Cook DJ, Ely EW Jr, Epstein SK, Fink $\mathrm{JB}$, Heffner JE, et al. Evidence-based guidelines for weaning and discontinuing ventilatory support: a collective task force facilitated by the American College of Chest Physicians; the American Association for Respiratory Care; and the American College of Critical Care Medicine. Chest. 2001;120(6 Suppl):375S-95S. http://dx.doi.org/10.1378/ chest.120.6_suppl.375S

22. Frutos-Vivar F, Esteban A, Apezteguia C, González M, Arabi Y, Restrepo Ml, et al. Outcome of reintubated patients after scheduled extubation. J Crit Care. 2011;26(5):502-9. http://dx.doi.org/10.1016/j.jcrc.2010.12.015

23. Savi A, Teixeira C, Silva JM, Borges LG, Pereira PA, Pinto KB, et al. Weaning predictors do not predict extubation failure in simple-to-wean patients. J Crit Care. 2012 Apr;27(2):221.e1-8. http://dx.doi.org/10.1016/j. jcrc.2011.07.079

24. Epstein SK. Decision to extubate. Intensive Care Med. 2002;28(5):535-46. http://dx.doi.org/10.1007/ s00134-002-1268-8

25. Whitaker IY. Gravidade do trauma e probabilidade de sobrevida em pacientes internados [thesis]. São
Paulo: Escola de Enfermagem da Universidade de São Paulo; 2000.

26. Namen AM, Ely EW, Tatter SB, Case LD, Lucia MA, Smith A, et al. Predictors of successful extubation in neurosurgical patients. Am J Respir Crit Care Med. 2001;163(3 Pt 1):658-64. http://dx.doi.org/10.1164/ ajrccm.163.3.2003060

27. Freitas EE, David CM. Avaliação do sucesso do desmame da ventilação mecânica. Rev Bras Ter Intensiva [serial on the Internet]. 2006 Dec [cited 2014 0ct 8];18(4):351-59. Available from: http://www.scielo.br/scielo.php?script=sci_ arttextCtpid=S0103-507X2006000400006Ctlng=en

28. Mokhlesi B, Tulaimat A, Gluckman TJ, Wang Y, Evans AT, Corbridge TC. Predicting extubation failure after successful completion of a spontaneous breathing trial. Respir Care. 2007;52(12):1710-7.

29. Su WL, Chen YH, Chen CW, Yang SH, Su CL, Perng WC, et al. Involuntary cough strength and extubation outcomes for patients in an ICU. Chest. 2010;137(4):77782. http://dx.doi.org/10.1378/chest.07-2808

30. Freitas FS, Parreira VF, Ibiapina CC. Aplicação clínica do pico de fluxo da tosse: uma revisão de literatura. Fisioter Mov. 2010;23(3):495-502. http://dx.doi.org/10.1590/ S0103-51502010000300016 